\title{
Sodium ferulate attenuates high-glucose-induced oxidative injury in HT22 hippocampal cells
}

\author{
JIANGPEI ZHAO ${ }^{1 *}$, LERONG LIU ${ }^{2 *}$, LINGXIAO ZHANG $^{2}$, JING $^{2}{ }^{3}$, \\ XUELI GUO ${ }^{4}, \mathrm{XIA} \mathrm{LI}^{2}$ and TONGFENG $\mathrm{ZHAO}^{2}$ \\ Departments of ${ }^{1}$ Neurology and ${ }^{2}$ Endocrinology, The Sixth Affiliated Hospital of Sun Yat-Sen University, Guangzhou, \\ Guangdong 510655; ${ }^{3}$ Department of Geriatric Medicine, Zhejiang Hospital, Hangzhou, Zhejiang 310013; \\ ${ }^{4}$ Department of Vascular Surgery, The First Affiliated Hospital of Zhengzhou University, \\ Zhengzhou, Henan 450000, P.R. China
}

Received August 20, 2018; Accepted June 20, 2019

DOI: $10.3892 /$ etm.2019.7822

\begin{abstract}
The aim of the present study was to investigate the protective effects of sodium ferulate (SF) on HT22 hippocampal cells under a high glucose concentration. Cells were cultured in normal glucose (25 mM D-glucose) or high glucose (50 mM D-glucose) with various concentrations of $\mathrm{SF}(50,100,250$ or $500 \mu \mathrm{M})$ for 0,48 and $72 \mathrm{~h}$. Cell viability was tested using a Cell Counting Kit-8 assay. Reactive oxygen species (ROS) production was detected using flow cytometry. The expression of nuclear factor erythroid 2-related factor 2 (Nrf2), heme oxygenase-1 (HO-1) and nuclear factor- $\kappa \mathrm{B}$ $(\mathrm{NF}-\kappa \mathrm{B})$ at the mRNA and protein levels were detected using a reverse transcription-quantitative polymerase chain reaction analysis and western blotting. HT22 hippocampal cell viability was revealed to be substantially decreased following culturing in high glucose medium $(50 \mathrm{mM})$ for 48 and $72 \mathrm{~h}$. The addition of $100 \mu \mathrm{M}$ SF abrogated this high-glucose-induced toxicity, but higher concentrations of SF $(250$ and $500 \mu \mathrm{M})$ were harmful to the cells. Furthermore, a high glucose concentration increased the generation of ROS, downregulated the expression of $\mathrm{Nrf} 2 / \mathrm{HO}-1$ and upregulated the expression of $\mathrm{NF}-\kappa \mathrm{B}$ subsequent to culturing for $72 \mathrm{~h}$, whereas the addition of the appropriate concentration of SF attenuated these effects. To the best of our knowledge, the present study is the first to report such results and provide evidence that SF protects HT22 cells from high glucose-induced toxicity by activating the $\mathrm{Nrf} 2 / \mathrm{HO}-1$ pathway and inhibiting the
\end{abstract}

Correspondence to: Professor Tongfeng Zhao, Department of Endocrinology, The Sixth Affiliated Hospital of Sun Yat-Sen University, 26 Erheng Road, Tianhe, Guangzhou, Guangdong 510655, P.R. China

E-mail: ztfzxy71@163.com

${ }^{*}$ Contributed equally

Key words: sodium ferulate, high glucose, hippocampus, nuclear factor erythroid 2-related factor 2, nuclear factor- $\mathrm{\kappa} B$ expression of $\mathrm{NF}-\kappa \mathrm{B}$, which may be of therapeutic value in diabetic encephalopathy.

\section{Introduction}

Diabetes is associated with chronic complications that affect almost every system in the body. In particular, the risk of diabetic encephalopathy has been increasingly recognized (1). Previous studies have reported that a high incidence of cognitive deficits, including Alzheimer's disease and vascular dementia, in addition to other types of dementia, is observed among patients with type 1 or 2 diabetes (1,2). Diabetic mouse models have also been reported to be associated with decreased hippocampal cell proliferation and survival, in line with reduced performance in learning and memory tests $(3,4)$. Multiple pathogenic mechanisms appear to be involved in the development of diabetic encephalopathy, including vascular dysfunction, hyperglycemia or hypoglycemia and the deficiency of or resistance to insulin (5). Studies in different experimental models have established that hyperglycemia reduces antioxidant levels and concomitantly increases the production of free radicals, which may contribute to neuronal dysfunction $(6,7)$. Therefore, developing novel antioxidants to antagonize oxidative stress is crucial for reducing diabetes-associated morbidity.

Accumulating evidence suggests that nuclear factor erythroid 2-related factor 2 (Nrf2) serves an important function in reducing oxidative stress in neurodegenerative disorders, demonstrated in in vitro and in vivo studies (8). Nrf2 exerts antioxidant effects by increasing the expression of endogenous antioxidant enzymes, including heme oxygenase-1 (HO-1), which may protect cells by catalyzing the degradation of heme to carbon monoxide, catalytic iron and bilirubin (9). Nrf2-deficienct mice exhibit more severe neurological disorders, along with higher levels of $\beta$-amyloid and tau protein (10), whilst the overexpression of Nrf2 resulted in the damage being reversed (11). It was reported that the activation of Nrf2 by sulforaphane, a pharmacological activator, observably improved cognitive functions in streptozotocin-induced type 1 diabetic rats, in addition 
to $\mathrm{db} / \mathrm{db}$ mice, by reducing hyperglycemia-induced neuronal apoptosis in the hippocampus $(12,13)$.

Ferulic acid (FA) belongs to the family of phenolic acids and is present in a wide variety of fruits, vegetables and grains $(14,15)$. FA has anti-inflammatory and antioxidant properties, and has been demonstrated to exert neuroprotective effects against cerebral ischemia-reperfusion injury (14) and Alzheimer's disease (15). Sodium ferulate (SF) is a sodium salt of FA, which is more stable in air and more easily dissolved in water (16). One previous study demonstrated that SF may increase antioxidant enzyme activity, thereby exerting protective effects in diabetic cardiomyopathy and other chronic complications of diabetes (16). However, to the best of our knowledge, no study to date has clearly demonstrated the function of SF in neuronal functions under high-glucose conditions. It was hypothesized that the protective effects of $\mathrm{SF}$ may be associated with the activation of the $\mathrm{Nrf} / \mathrm{HO}-1$ pathway. The aim of the present study was to investigate the protective function of SF in high-glucose cultured HT22 hippocampal cells and elucidate the underlying mechanisms.

\section{Materials and methods}

Cell culture. The HT22 mouse hippocampal cell line was obtained from Jennio Biotech Co., Ltd. (Guangzhou, China). Cells were cultured in Dulbecco's modified Eagle's medium (Gibco; Thermo Fisher Scientific, Inc., Waltham, MA, USA) with normal $(25 \mathrm{mM})$ or high $(50 \mathrm{mM})$ glucose concentrations, supplemented with $10 \%$ fetal bovine serum (Biological Industries, Kibbutz Beit Haemek, Israel). SF (Shandong XiYa Chemical Industry Co., Ltd., Shandong, China) was added to the high-glucose group at various concentrations (50, 100, 250, $500 \mu \mathrm{M}$ ), followed by incubation at $37^{\circ} \mathrm{C}$ with $5 \% \mathrm{CO}_{2}$ in a humidified atmosphere.

Cell Counting Kit-8 (CCK-8) assay. HT22 cells in the logarithmic growth phase were plated onto 96 -well plates at a density of $4 \times 10^{4}$ cells per well. Cell viability was estimated using a CCK-8 assay, according to the manufacturer's protocol (Dojindo Molecular Technologies, Inc., Kumamoto, Japan). CCK-8 was added into each well at 0,48 and $72 \mathrm{~h}$ following culturing, and then incubated for $3 \mathrm{~h}$ at $37^{\circ} \mathrm{C}$ prior to measurement. Absorbance at $450 \mathrm{~nm}$ was detected using a microplate reader (Multiskan ${ }^{\mathrm{TM}}$ FC; Thermo Fisher Scientific, Inc.).

RNA extraction and reverse transcription-quantitative polymerase chain reaction $(R T-q P C R)$ analysis. Total RNA was extracted from the cells using TRIzol reagent (Takara Bio, Inc., Otsu, Japan). cDNA was synthesized from total RNA using a two-temperature cycle at $37^{\circ} \mathrm{C}$ for $15 \mathrm{~min}$ and $85^{\circ} \mathrm{C}$ for $5 \mathrm{sec}$ using Prime-Script ${ }^{\mathrm{TM}} \mathrm{RT}$ reagent kits with gDNA eraser (Takara Bio, Inc.), according to the manufacturer's protocol. mRNA expression levels were measured using RT-qPCR on Biosystems 7500 (Applied Biosystems, Inc., Carlsbad, Cal, USA). Reaction mixtures (10 $\mu \mathrm{l})$ contained SYBR Select Master Mix (Takara Bio, Inc.), (5 $\mu \mathrm{l})$ cDNA samples $(1 \mu \mathrm{l})$ and forward or reverse primers $(0.5 \mu \mathrm{l})$. A two-temperature cycle at $95^{\circ} \mathrm{C}$ for $10 \mathrm{sec}$ and $60^{\circ} \mathrm{C}$ for $30 \mathrm{sec}$ was run and repeated for 40 cycles. Relative quantities of sample transcripts were calculated using the
$2^{-\Delta \Delta \mathrm{Cq}}$ method (17) with GAPDH used as a reference gene. All samples were expressed relative to the mean. The primer sequences used are listed in Table I.

Gel electrophoresis and western blotting. Cell lysates were prepared using radioimmunoprecipitation assay lysis buffer (CW Biotech) in the presence of a protease inhibitor cocktail (Thermo Fisher Scientific, Inc.). Protein concentrations of cell lysates were quantified using a Pierce BCA Protein Assay kit (Thermo Fisher Scientific, Inc.) according to the manufacturer's protocol. Total protein (10 ug) were loaded in each well of $12 \%$ sodium dodecyl sulfate polyacrylamide gel and subjected to electrophoresis. The proteins were then transferred onto polyvinylidene fluoride membranes (EMD Millipore, Billerica, MA, USA). The membranes were blocked with 5\% non-fat milk for $1 \mathrm{~h}$ at room temperature and incubated with primary antibodies against GAPDH (1:5,000; cat. no. 10494-1-AP; ProteinTech Group, Inc.), Nrf2 (1:1,000; cat. no. ab62352; Abcam), HO-1 (1:1,000; cat. no. ab13243; Abcam) and NF- $\kappa$ B (1:10,000; cat. no. ab16502; Abcam) at $4^{\circ} \mathrm{C}$ overnight, followed by incubation with a horseradish peroxidase-conjugated secondary antibody (1:5,000; cat. no. SA00001-2; ProteinTech Group, Inc.) for $1 \mathrm{~h}$ at room temperature. Detection was performed using ECL Plus western blotting detection reagents (EMD Millipore) and the blots were semi-quantified using Image 2 (National Institute of Health).

Measurement of reactive oxygen species (ROS) generation. Cells were cultured in 6 -well plates for 0 or $72 \mathrm{~h}$, then washed with phosphate-buffered saline (HyClone; GE Healthcare, Logan, UT, USA) and incubated with $5 \mu \mathrm{M}$ CellROX ${ }^{\circledR}$ Deep Red Reagent (Molecular Probes; Thermo Fisher Scientific, Inc.) in completed medium for $30 \mathrm{~min}$ at $37^{\circ} \mathrm{C}$. Subsequently, cells were examined using a flow cytometer (BD FACScanto II; BD Biosciences) and data was analyzed using FlowJo (V10.0; BD Biosciences).

Statistical analysis. The data were expressed as the mean \pm standard deviation. One-way analysis of variance followed by a least significant difference post-hoc test was used to compare the mean values amongst control and treatment groups using SPSS17.0 software (SPSS, Inc., Chicago, IL, USA). $\mathrm{P}<0.05$ was considered to indicate a statistically significant difference.

\section{Results}

SF preserves HT22 cell viability under high-glucose conditions. The present study established an in vitro model of hippocampal neuron cells exposed to a high glucose concentration $(50 \mathrm{mM})$, as previously reported (18). To verify the effects of SF, HT22 cells were exposed to high glucose $(50 \mathrm{mM})$ with various concentrations of SF $(50,100,250$ and $500 \mu \mathrm{M})$ for 0 , 48 and $72 \mathrm{~h}$. Cell viability was determined using a CCK-8 assay. Compared with the normal-glucose group, the high-glucose group without SF exhibited a significant decrease $(\mathrm{P}<0.01)$ in cell viability subsequent to culturing for 48 or $72 \mathrm{~h}$. The addition of $50 \mu \mathrm{M}$ SF to the high-glucose group did not significantly affect cell viability at $72 \mathrm{~h}$. However, when $100 \mu \mathrm{M}$ $\mathrm{SF}$ was added to the high-glucose group, the cell viability 
Table I. Primers for reverse transcription-quantitative polymerase chain reaction.

\begin{tabular}{lll}
\hline Gene & \multicolumn{1}{c}{ Forward primers } & \multicolumn{1}{c}{ Reverse primers } \\
\hline $\begin{array}{l}\text { Nuclear factor erythroid } \\
\text { 2-related factor 2 }\end{array}$ & 5'-GAAATGATGTCCAAGGAGCAA-3' & 5'-AAGACTTCAAGATACAAGGTGCTG-3' \\
Nuclear factor-kB & 5'-ACCCTGAAATCAAAGACAAAGAG-3' & 5'-GAAATCCGTAGTTCGAGTAGCC-3' \\
Heme oxygenase-1 & 5'-TGACAGAAGAGGCTAAGACCG-3' & 5'-GTGAGGACCCACTGGAGGA-3' \\
GAPDH & 5'-ATTCAACGGCACAGTCAAGG-3' & 5'-CACCAGTGGATGCAGGGAT-3' \\
\hline
\end{tabular}

increased significantly compared with the high-glucose alone group $(\mathrm{P}<0.01)$, to levels comparable with those in the normal-glucose group. However, cell viability did not increase further with higher $(250$ and $500 \mu \mathrm{M})$ concentrations of SF (Fig. 1).

SF upregulates Nrf2-1 expression levels in HT22 cells. The Nrf2 mRNA levels in HT22 cells cultured with a high glucose concentration were significantly downregulated compared with those in the normal-glucose group at $72 \mathrm{~h}(\mathrm{P}<0.01)$. Following the addition of different concentrations of SF (50, 100, 250 and $500 \mu \mathrm{M}$ ) to each group for $72 \mathrm{~h}$, the Nrf2 mRNA levels were significantly increased compared with those in the high-glucose group without SF $(\mathrm{P}<0.01)$, to levels even higher compared with those in the normal-glucose group. Subsequently, western blotting was performed to determine the expression levels of the Nrf2 protein. However, upon increasing the expression of the Nrf2 protein with different concentrations of SF $(50,100$, 250 and $500 \mu \mathrm{M}$ ) was significantly upregulated compared to the high glucose group. ( $\mathrm{P}<0.01$; Fig. 2$)$.

SF upregulates HO-1 expression levels in HT22 cells. HO-1 mRNA and protein expression levels were significantly decreased when HT22 cells were exposed to a high glucose concentration for $72 \mathrm{~h}$ compared with the normal glucose group $(\mathrm{P}<0.01)$. Subsequent to culturing with $\mathrm{SF}(50,100$, 250 and $500 \mu \mathrm{M})$, the expression levels of HO-1 were significantly increased compared with that in the high-glucose and normal-glucose groups $(\mathrm{P}<0.01$; Fig. 2).

SF downregulates $N F-\kappa B$ expression levels in HT22 cells. The expression of $\mathrm{NF}-\kappa \mathrm{B}$ at the mRNA and protein levels was determined using RT-qPCR and western blotting, respectively. The results demonstrated that the mRNA and protein levels of NF- $\mathrm{NB}$ in HT22 cells in the high-glucose group were significantly upregulated compared with the normal-glucose group at $72 \mathrm{~h}(\mathrm{P}<0.01)$. High-glucose group with SF at $50,100,250$ or $500 \mu \mathrm{M}$ significantly downregulated the expression of NF- $\kappa \mathrm{B}$ mRNA in a concentration-dependent manner compared with the high glucose alone group $(\mathrm{P}<0.01$; Fig. 2$)$.

SF inhibits the production of ROS. The intracellular ROS levels were measured using flow cytometry. HT22 cells subjected to a high glucose concentration exhibited a significant increase in fluorogenic intensity compared with the normal glucose group $(\mathrm{P}<0.01)$, which meant an increase in cellular ROS. This effect was inhibited by SF. Therefore, high glucose increased ROS production in HT22 cells, whereas SF (50, $100 \mu \mathrm{M})$ significantly attenuated this high-glucose-induced ROS generation compared with the high glucose group ( $\mathrm{P}<0.01$; Fig. 3$)$.

\section{Discussion}

HT22 is a hippocampal neuronal cell line that has been widely used in in vitro models to study the mechanisms underlying neurodegenerative diseases. In the present study, an in vitro model mimicking hyperglycemia was designed to investigate the protective effect of SF on HT22 cells. It was observed that high glucose levels increased ROS production and decreased the viability of HT22 cells, which was induced by downregulating Nrf2/HO-1 pathway activation and upregulating NF- $\mathrm{B}$.

Hyperglycemia is associated with increased oxidative stress. Enhanced ROS production and oxidative injury serve a key function in the progression of diabetic encephalopathy (19). It has been reported that FA exerts protective effects against amyloid- $\beta$-induced neurodegeneration (20). FA has been demonstrated to protect cortical synaptosomal membranes by reducing protein oxidation, lipid peroxidation and cell death induced by oxidative radicals (21). The present study demonstrated the cytoprotective effects of SF at concentrations of 50 and $100 \mu \mathrm{M}$ by decreasing ROS production; however, higher concentrations of SF (250 and $500 \mu \mathrm{M})$ decreased cell viability, consistent with the results of previous studies $(20,21)$. Therefore, a more precise safe dose of SF must be determined in future studies.

SF functions as a direct scavenger of ROS. This characteristic certainly contributes to its neuroprotective effects (22) In addition to their antioxidant properties, a number of polyphenols, including SF, appear to exert pleiotropic effects on cells and tissues (22). The Nrf2/HO-1 pathway serves an important function in the regulation of cellular redox status. When cells are exposed to ROS, Nrf2 translocates to the nucleus and binds to antioxidant response elements, inducing the production of endogenous antioxidant enzymes to restore cellular homeostasis (23). FA has been revealed to induce HO-1 expression via activating extracellular signal-regulated kinase, thus protecting lymphocytes from radiation-induced injury (24). It was demonstrated that FA protects neuroblastoma cells from oxidative injury through upregulating $\mathrm{HO}-1$ expression and the biliverdin reductase system by fostering the nuclear translocation of the transcriptional activator Nrf2 (25). Ethyl ferulate, a naturally occurring ester of FA, was also proven to protect rat neurons against oxidative stress 


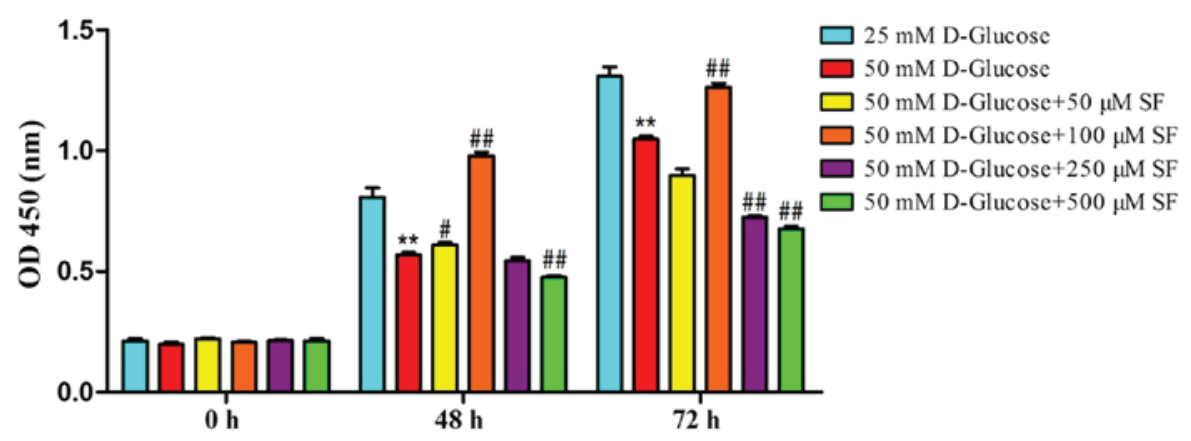

Figure 1. Effect of SF on cell viability. HT22 cells were treated with normal glucose $(25 \mathrm{mM})$ or high glucose $(50 \mathrm{mM})$ under various concentrations of SF for 0,48 and $72 \mathrm{~h}$. Cell viability was measured using a Cell Counting Kit-8 assay as described. Values are expressed as the mean \pm standard deviation ( $\mathrm{n}=3$ for each group). ${ }^{* *} \mathrm{P}<0.01$ vs. normal glucose group $(25 \mathrm{mM}) ;{ }^{*} \mathrm{P}<0.05$ and ${ }^{\# \#} \mathrm{P}<0.01$ vs. high glucose alone group (50 mM). SF, sodium ferulate; OD, optical density.
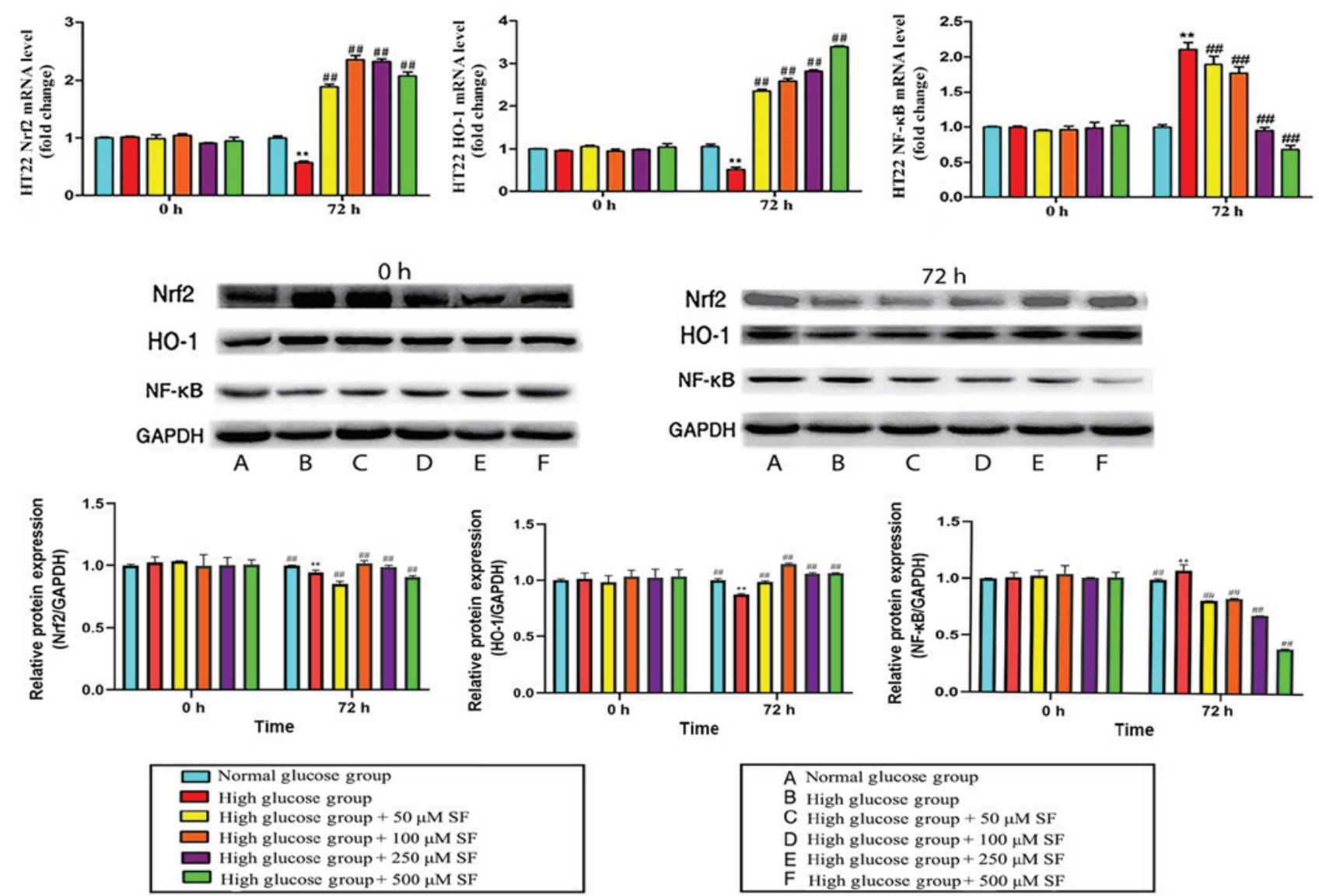

Figure 2. Effect of SF on Nrf2, HO-1 and NF-kB expression. HT22 cells were treated with normal glucose ( $25 \mathrm{mM})$ or high glucose (50 mM) in the absence or presence of various concentrations of SF for 0 and $72 \mathrm{~h}$. The mRNA and protein levels in HT22 cells were assessed using reverse transcription-quantitative polymerase chain reaction and western blotting. Data were expressed as the mean \pm standard deviation ( $\mathrm{n}=3$ for each group). ${ }^{* *} \mathrm{P}<0.01$ vs. normal glucose group $(25 \mathrm{mM}) ;{ }^{\# /} \mathrm{P}<0.01$ vs. high glucose alone group $(50 \mathrm{mM})$. SF, sodium ferulate; Nrf2, nuclear factor erythroid 2-related factor 2; HO-1, heme oxygenase-1; $\mathrm{NF}-\kappa \mathrm{B}$, nuclear factor- $\mathrm{kB}$.

by promoting the expression of HO-1 at the mRNA and protein levels (26). The present study demonstrated that SF upregulated Nrf2/HO-1 mRNA and protein expression levels in HT22 cells. Although Nrf2/HO-1 was revealed to be implicated in the neuroprotective effect of SF, the causal association remains unclear. To further confirm this association, a Nrf2 knockout model is required to verify whether this protective effect is attenuated when Nrf2 expression is downregulated.
$\mathrm{NF}-\mathrm{\kappa B}$ is a transcription factor that regulates the expression of multiple cytokines, including tumor necrosis factor- $\alpha$, interleukin (IL)- $1 \beta$ and IL-8, and serves a key function in oxidative stress and inflammation (27). One previous study suggests that the activation of NF- $\mathrm{kB}$ and its downstream genes are implicated in the pathobiology of diabetes and its complications (28). The persistent activation of NF- $\mathrm{\kappa B}$ was demonstrated in the hippocampi of streptozotocin-induced diabetic rats (29). SF was reported to protect hippocampal neurons against 


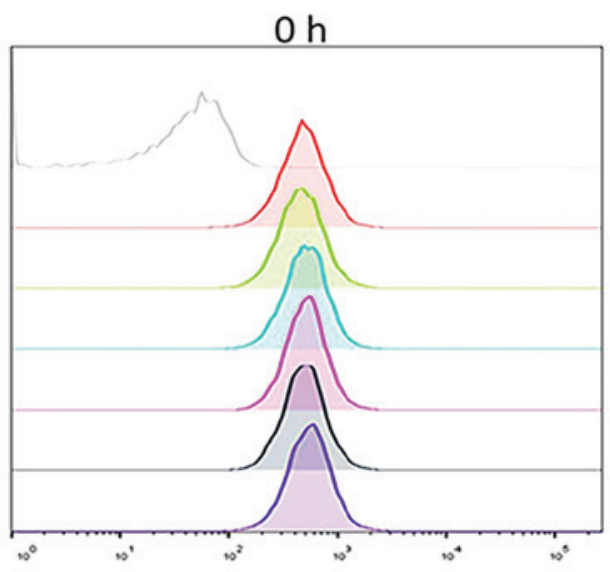

APC
$72 \mathrm{~h}$

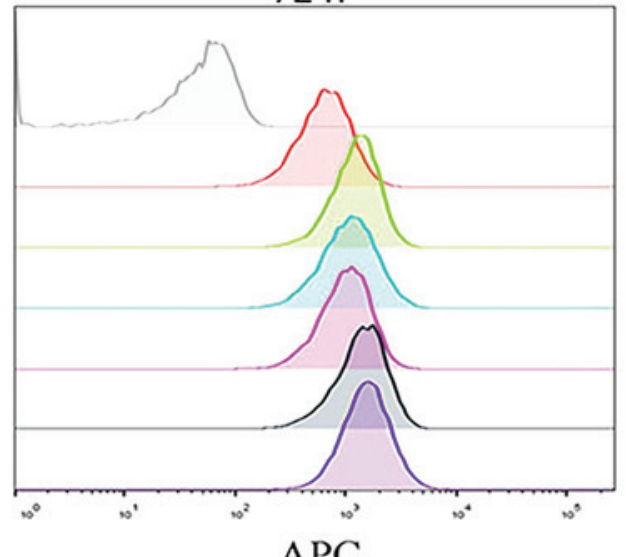

APC

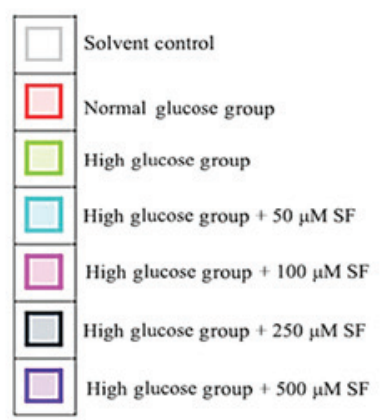

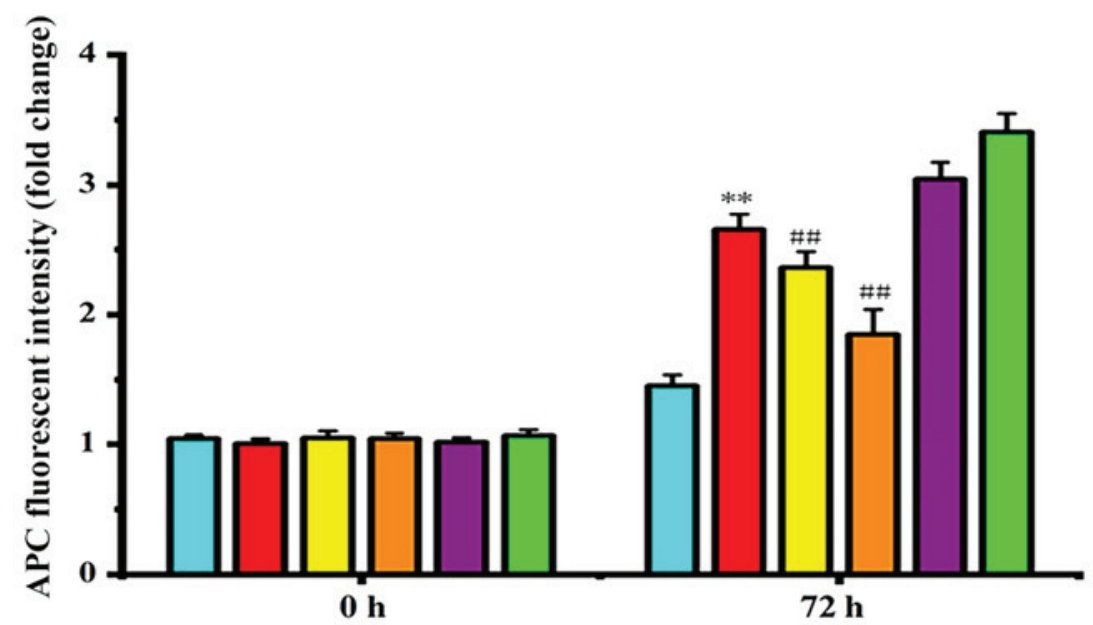

Figure 3. Effect of SF on ROS production. HT22 cells were treated with normal glucose ( $25 \mathrm{mM})$ or high glucose (50 mM) in the absence or presence of various concentrations of SF for 0 and $72 \mathrm{~h}$. ROS was measured using flow cytometer. The fluorescence intensity was associated with ROS level. It was observed that the fluorescence intensity was significantly decreased in HT22 cells in the SF groups with 50 or $100 \mu \mathrm{M}$ compared with groups not treated with SF. ** $\mathrm{P}<0.01$ vs. normal glucose group $(25 \mathrm{mM}) ;{ }^{\# \#} \mathrm{P}<0.01 \mathrm{vs}$. high glucose alone group $(50 \mathrm{mM})$. SF, sodium ferulate; ROS, reactive oxygen species.

sodium nitroprusside-induced toxicity and decrease the expression of NF-кB P65 (30). Furthermore, SF may markedly prevent amyloid $\beta$-induced IL-1 $\beta$ increase and inhibit neuronal apoptotic death in a rat hippocampus (31). The results of the present study suggest that SF may prevent the high-glucose-induced activation of $\mathrm{NF}-\kappa \mathrm{B}$.

In conclusion, SF increases the resistance of HT22 cells to glucose toxicity by activating the $\mathrm{Nrf} 2 / \mathrm{HO}-1$ pathway and inhibiting the expression of $\mathrm{NF}-\kappa \mathrm{B}$, thereby attenuating high-glucose-induced neuronal death and indicating potential novel strategies for neuroprotection in diabetic encephalopathy.

\section{Acknowledgements}

Not applicable.

\section{Funding}

The present study was supported by the Science and Technology Planning Project of Guangdong Province, China (grant no. 2014A020212534), the Science and Technology Planning Project of Guangzhou, China (grant no. 201604020119) and the Medical Scientific Research Foundation of Zhejiang Province, China (grant no. 2016KYA0005).

\section{Availability of materials and data}

The datasets used and/or analyzed during the current study are available from the corresponding author on reasonable request.

\section{Authors' contributions}

JZ contributed to the conception of the study and was a major contributor in writing the manuscript. TZ designed the present study, interpreted the results, wrote and revised the manuscript and gave final approval of the version to be published. LL performed the experiments. LZ contributed to statistics and data analysis, drafting and revising the manuscript, and making the figures. JL, XG and XL helped to perform the experiments.

\section{Ethics approval and consent to participate}

Not applicable. 


\section{Patient consent for publication}

Not applicable.

\section{Competing interests}

The authors declare that they have no competing interests.

\section{References}

1. Xu WL, von Strauss E, Qiu CX, Winblad B and Fratiglioni L: Uncontrolled diabetes increases the risk of Alzheimer's disease: A population-based cohort study. Diabetologia 52: 1031-1039, 2009.

2. van Harten B, Oosterman J, Muslimovic D, van Loon BJ, Scheltens $\mathrm{P}$ and Weinstein HC: Cognitive impairment and MRI correlates in the elderly patients with type 2 diabetes mellitus. Age Ageing 36: 164-170, 2007.

3. Li ZG, Zhang W and Sima AA: Alzheimer-like changes in rat models of spontaneous diabetes. Diabetes 56: 1817-1824, 2007.

4. Alvarez EO, Beauquis J, Revsin Y, Banzan AM, Roig P, De Nicola AF and Saravia F: Cognitive dysfunction and hippocampal changes in experimental type 1 diabetes. Behav Brain Res 198: 224-230, 2009.

5. Sima AA: Encephalopathies: The emerging diabetic complications. Acta Diabetol 47: 279-293, 2010.

6. Russell JW, Golovoy D, Vincent AM, Mahendru P, Olzmann JA, Mentzer A and Feldman EL: High glucose-induced oxidative stress and mitochondrial dysfunction in neurons. FASEB J 16: 1738-1748, 2002.

7. Kamboj SS and Sandhir R: Protective effect of N-acetylcysteine supplementation on mitochondrial oxidative stress and mitochondrial enzymes in cerebral cortex of streptozotocin-treated diabetic rats. Mitochondrion 11: 214-222, 2011.

8. Karkkainen V, Pomeshchik Y Savchenko E, Dhungana H, Kurronen A, Lehtonen S, Naumenko N, Tavi P, Levonen AL, Yamamoto $\mathrm{M}$, et al: Nrf2 regulates neurogenesis and protects neural progenitor cells against $\mathrm{A} \beta$ toxicity. Stem Cells 32 1904-1916, 2014.

9. Baird L and Dinkova-Kostova AT: The cytoprotective role of the Keap1-Nrf2 pathway. Arch Toxicol 85: 241-272, 2011.

10. Rojo AI, Pajares M, Rada P, Nuñez A, Nevado-Holgado AJ, Killik R, Van Leuven F, Ribe E, Lovestone S, Yamamoto M and Cuadrado A: NRF2 deficiency replicates transcriptomic changes in Alzheimer's patients and worsens APP and TAU pathology. Redox Biol 13: 444-451, 2017.

11. Kanninen K, Malm TM, Jyrkkänen HK, Goldsteins G, Keksa-Goldsteine V, Tanila H, Yamamoto M, Yia-Herttuala S, Levonen AL and Koistinaho J: Nuclear factor erythroid 2-related factor 2 protects against beta amyloid. Mol Cell Neurosci 39: 302-313, 2008

12. Wang G, Fang H, Zhen Y, Xu G, Tian J, Zhang Y, Zhang D, Zhang G, Xu J, Zhang Z, et al: Sulforaphane prevents neuronal apoptosis and memory impairment in diabetic rats. Cell Physiol Biochem 39: 901-907, 2016.

13. Pu D, Zhao Y, Chen J, Sun Y, Lv A, Zhu S, Luo C, Zhao K and Xiao Q: Protective effects of sulforaphane on cognitive impairments and AD-like lesions in diabetic mice are associated with the upregulation of Nrf2 transcription activity. Neuroscience 381: 35-45, 2018.

14. Ren Z, Zhang R, Li Y, Li Y, Yang Z and Yang H: Ferulic acid exerts neuroprotective effects against cerebral ischemia/reperfusion-induced injury via antioxidant and anti-apoptotic mechanisms in vitro and in vivo. Int J Mol Med 40: 1444-1456, 2017.
15. Mancuso $\mathrm{C}$ and Santangelo R: Ferulic acid: Pharmacological and toxicological aspects. Food Chem Toxicol 65: 185-195, 2014.

16. Xu X, Xiao H, Zhao J and Zhao T: Cardioprotective effect of sodium ferulate in diabetic rats. Int J Med Sci 9: 291-300, 2012.

17. Livak KJ and Schmittgen TD: Analysis of relative gene expression data using real-time quantitative PCR and the 2(-Delta Delta C(T)) method. Methods 25: 402-408, 2001

18. Ward R and Ergul A: Relationship of endothelin-1 and NLRP3 inflammasome activation in HT22 hippocampal cells in diabetes. Life Sci 159: 97-103, 2016.

19. Rolo AP and Palmeira CM: Diabetes and mitochondrial function: Role of hyperglycemia and oxidative stress. Toxicol Appl Pharm 212: 167-178, 2006.

20. Kikugawa M, Tsutsuki H, Ida T, Nakajima $H$, Ihara $H$ and Sakamoto T: Water-soluble ferulic acid derivatives improve amyloid-beta-induced neuronal cell death and dysmnesia through inhibition of amyloid- $\beta$ aggregation. Biosci Biotechnol Biochem 80: 547-553, 2016.

21. Kanski J, Aksenova M, Stoyanova A and Butterfield DA: Ferulic acid antioxidant protection against hydroxyl and peroxyl radical oxidation in synaptosomal and neuronal cell culture systems in vitro: Structure-activity studies. J Nutr Biochem 13: 273-281, 2002.

22. Jiang $X$, Lin Q, He G, Hou X, Shan Z and Du Y: Therapeutic effect of QQL prescription on type 2 diabetic rats. Chin J Pathophysiol 33: 1794-1800, 2017.

23. de Vries HE, Witte M, Hondius D, Rozemuller AJ, Drukarch B, Hoozemans J and van Horssen J: Nrf2-induced antioxidant protection: A promising target to counteract ROS-mediated damage in neurodegenerative disease? Free Radic Biol Med 45: 1375-1383, 2008

24. Ma ZC, Hong Q, Wang YG, Liang QD, Tan HL, Xiao CR, Tang XL, Shao S, Zhou SS and Gao Y: Ferulic acid induces heme oxygenase-1 via activation of ERK and Nrf2. Drug Discov Ther 5: 299-305, 2011.

25. Catino S, Paciello F, Miceli F, Rolesi R, Troiani D, Calabrese V, Santangelo $\mathrm{R}$ and Mancuso $\mathrm{C}$ : Ferulic acid regulates the Nrf2/Heme oxygenase-1 system and counteracts trimethyltin-induced neuronal damage in the human neuroblastoma cell line SH-SY5Y. Front Pharmacol 6: 305, 2015.

26. Scapagnini G, Butterfield DA, Colombrita C, Sultana R, Pascale A and Calabrese V: Ethyl ferulate, a lipophilic polyphenol, induces HO-1 and protects rat neurons against oxidative stress. Antioxid Redox Signal 6: 811-818, 2004.

27. Mezzasoma L, Antognelli $C$ and Talesa VN: A novel role for brain natriuretic peptide: Inhibition of IL-1 $\beta$ secretion via downregulation of NF-kB/Erk 1/2 and NALP3/ASC/Caspase-1 activation in human THP-1 monocyte. Mediators Inflamm 2017: 5858315,2017

28. Wang B, Miao Y, Zhao Z and Zhong Y: Inflammatory macrophages promotes development of diabetic encephalopathy. Cell Physiol Biochem 36: 1142-1150, 2015.

29. Aragno M, Mastrocola R, Brignardello E, Catalano M, Robino G, Manti R, Parola M, Danni O and Boccuzzi G: Dehydroepiandrosterone modulates nuclear factor-kappaB activation in hippocampus of diabetic rats. Endocrinology 143: 3250-3258, 2002.

30. Zhang H, Li Y and An Y: Effect of sodium ferulate on NF- $\mathrm{B}$ P65 and Par-4 expression of apoptotic hippocampal neurons induced by SNP. Chin J Gerontol 28: 1361-1364, 2008 (In Chinese).

31. Jin Y, Yan EZ, Li XM, Fan Y, Zhao YJ, Liu Z and Liu WZ: Neuroprotective effect of sodium ferulate and signal transduction mechanisms in the aged rat hippocampus. Acta Pharmacol Sin 29: 1399-1408, 2008.

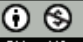

This work is licensed under a Creative Commons Attribution 4.0 International (CC BY-NC 4.0) License 